$\longleftarrow$ SPECHALTSSUEON

\title{
ENERGY TRANSFER IN THE WESTERN TROPICAL PACIFIC
}

By Sarah E. Zedler, Brian S. Powell, Bo Qiu, and Daniel L. Rudnick
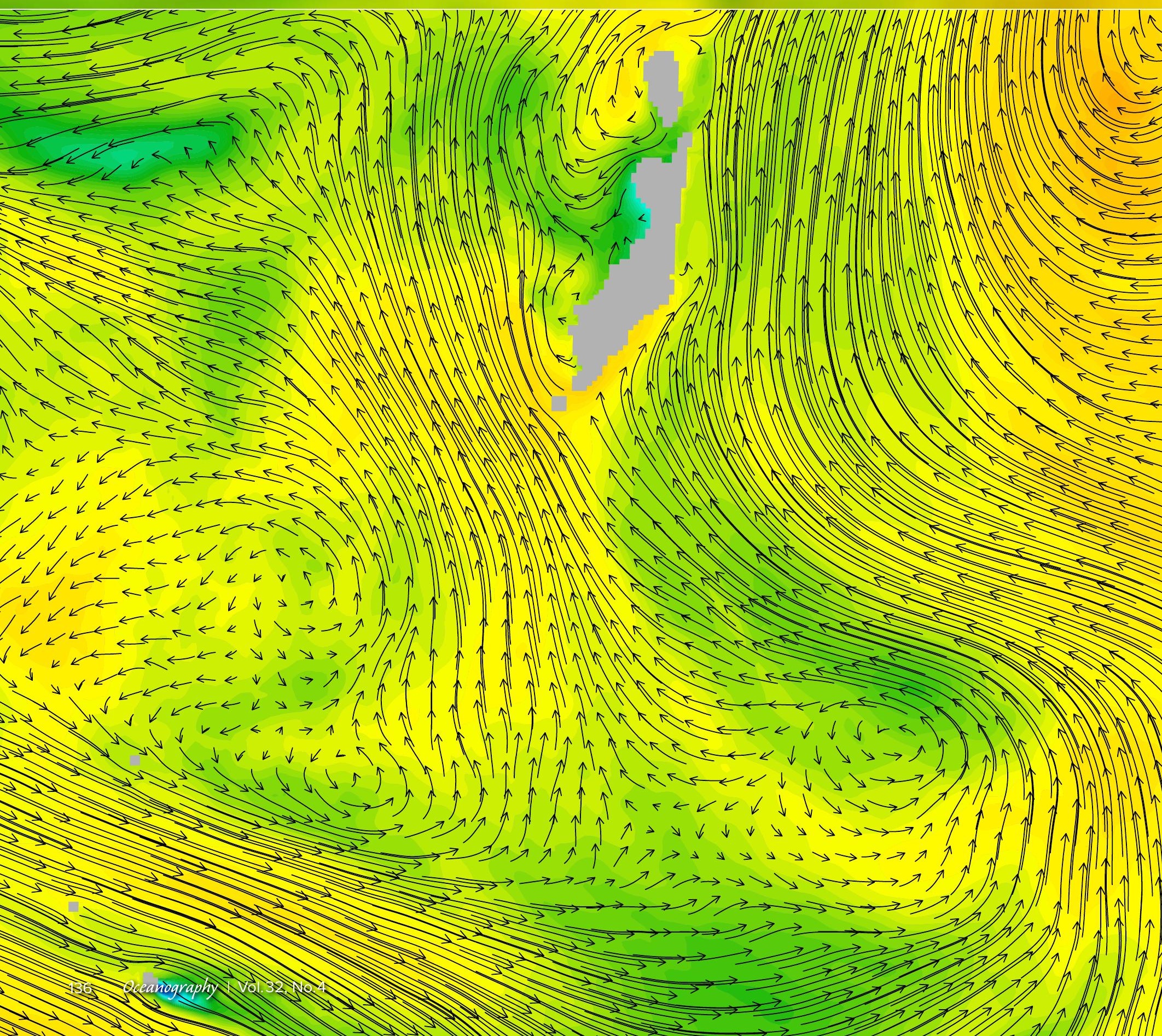
ABSTRACT. We aim to understand the surface kinetic energy cascade across a wide range of length scales in the western tropical Pacific (WTP) and the influence of both climatic dynamics and topography using a high-resolution $(2.5 \mathrm{~km})$ model nested within a coarser $(8 \mathrm{~km})$ state-estimate model. The period of interest includes the development and realization of the 2014-2015 El Niño. The energy cascade in the WTP is similar to that of the extratropics, with simultaneous dual inverse and forward cascades of kinetic energy to larger and smaller scales, with the strongest source of energy near the local baroclinic Rossby radius. We find that topography enhances the strength of the mean surface cascades in both forward and inverse directions, altering the energy transfer in the WTP on both long timescales important for determining the mean distribution of kinetic energy across a range of length scales and short timescales relevant for dynamical prediction.

IN PLAIN WORDS. Wind, tides, and other processes put energy into the ocean. Understanding whether this energy goes into the large circulation flows around the globe (inverse cascade) or is lost to friction (forward cascade) is important when trying to predict the ocean over days to years. In this paper, we use three different numerical model simulations to examine the western tropical Pacific around the island nation of Palau to identify where the energy goes when flows encounter the islands and how the islands change this transfer. We find that the flows that interact with the islands help move energy into both small and large flows. Around Palau, energy is primarily put into the ocean at around $200 \mathrm{~km}$ length, which corresponds to eddies (storms in the ocean) and winds. We find that to properly capture this inverse energy cascade requires a fine resolution numerical model that can represent the islands. Without islands included, the energy that goes into the large circulation flows is lost, and that will affect longerterm predictions. This result demonstrates that flows encountering steep topography play a key role in moving energy from one scale to others. This energy transfer is important to the ecology and predictability of the western tropical Pacific.

\section{INTRODUCTION}

The canonical wind-forced upper ocean circulation in the North Pacific Ocean consists of a basin-wide, asymmetrical, clockwise rotating subtropical gyre with an intensified northward boundary current, the Kuroshio, on its western side, and a broad, weak, southward current in the east (Sverdrup, 1947). Between about $17^{\circ} \mathrm{N}$ and $25^{\circ} \mathrm{N}$, a vigorous field of mesoscale eddies form in the eastward-flowing and baroclinically unstable Subtropical Countercurrent (STCC; Figure 1; Qiu, 1999; Qiu and Chen, 2010). At lower latitudes $\left(7^{\circ}-21^{\circ} \mathrm{N}\right)$, the southern branch of the subtropical gyre forms the stable

OPPOSITE PAGE. A snapshot from the $2.5 \mathrm{~km}$ model of the western tropical Pacific (zoomed to Palau) described in this paper showing the sea surface temperature and velocity during the end of the 2014-2015 El Niño and the northward flow of the North Equatorial Countercurrent. nonlinear momentum budget (Arruda and Nof, 2003).

The western tropical Pacific (WTP) is distinguished from mid-latitudes by a weak Coriolis force with a strong change in relative vorticity with latitude displacement ( $\beta$-effect) and relatively consistent heating throughout the year that leads to a muted seasonal cycle (Bathen, 1972) and a deep isothermal layer (Chang, 1993). Combined with heavy rainfall that maintains a barrier layer (shallower halocline than thermocline), stratification in the WTP is strong relative to other ocean regions (Emery et al., 1984). Observations provide evidence that surface layer currents in the tropical Pacific are roughly in geostrophic balance (E.S. Johnson et al., 1988; Lagerloef et al., 1999), and they are an ageostrophic component of the flow.

Another distinguishing feature of the WTP is its highly variable topography. A series of outcropping volcanic ridges make up the Mariana Island chain $\left(14^{\circ}-25^{\circ} \mathrm{N}, \quad 140^{\circ}-145^{\circ} \mathrm{E}\right)$, and southwest of the Marianas, a number of small islands dot the ocean. These include Palau $\left(6^{\circ}-8.5^{\circ} \mathrm{N}, 134.5^{\circ} \mathrm{E}\right)$, where very steep bottom topography features act as barriers, disrupting mean currents and barotropic tides. The islands play a dual role-as a source of energy by initiating development of internal waves and eddies on the one hand, and as an energy sink, through bottom friction and form drag, on the other. The eddies (Huppert and Bryan, 1976; Dong and McWilliams, 2007), internal tides (Schott, 1977; Holloway and Merrifield, 1999), lee waves (Bell, 1975), inertial waves (Nikurashin and Ferrari, 2010), submesoscale (Capet et al., 2008b), and other flow features that form in the presence of the islands contribute to a transfer of kinetic energy a different range of length scales than the source. Rhines and Bretherton (1973) and Reznik and Tsybaneva (1999) used two-layer models to characterize the effects of topography on the structure of the first baroclinic mode. Both studies found that rough topography can affect surface layer flow.

Observations indicate that in the 
extratropics, there is an inverse cascade of kinetic energy toward larger length scales, and the possibility of a forward cascade at smaller length scales (Scott and Wang, 2005; Arbic et al., 2013). Geostrophically balanced motions at scales close to the first baroclinic Rossby radius participate in an inverse cascade. At smaller scales, lateral buoyancy gradients at the surface can lead to shallow baroclinic instabilities in the mixed layer that transfer available potential to kinetic energy in an inverse cascade as they restratify the mixed layer (Boccaletti et al., 2007). Surface buoyancy gradients can also participate in a forward cascade through the process of frontogenesis (Capet et al., 2008a). The features that distinguish the dynamical regimes of the western tropical Pacific from other regions may be responsible for differences in the characteristic energy transfer that may alter regional predictability. The goals of this paper are: (1) to characterize the energy flow in the western Tropical Pacific, and (2) to assess the effects of the island barriers on the horizontal energy transfer at the surface, with the underlying goal of understanding the further-reaching implications they may have for predictability.

Theoretical modeling experiments conducted for idealized ocean environments support the observational findings of Scott and Wang (2005), suggesting that non-rotating, stratified three-dimensional fluids exhibit forward cascades, whereas two-dimensional geostrophically balanced fluids produce inverse, total energy cascades (potential plus kinetic; Lindborg, 2006; Salmon, 1998). Early studies in flat-bottomed, rotational domains disagreed, however, on the direction of energy flow in the baroclinic mode(s) (Fu and Flierl, 1980; Salmon, 1998). More recent investigations indicate that the rotational-or geostrophic-part of the flow has an upscale kinetic energy transfer, whereas the divergent-ageostrophic-part is downscale (Capet et al., 2008b; Brüggemann and Eden, 2015; Marino et al., 2015), and furthermore that these dualdirection cascades can exist simultaneously (Callies and Ferrari, 2013; Marino

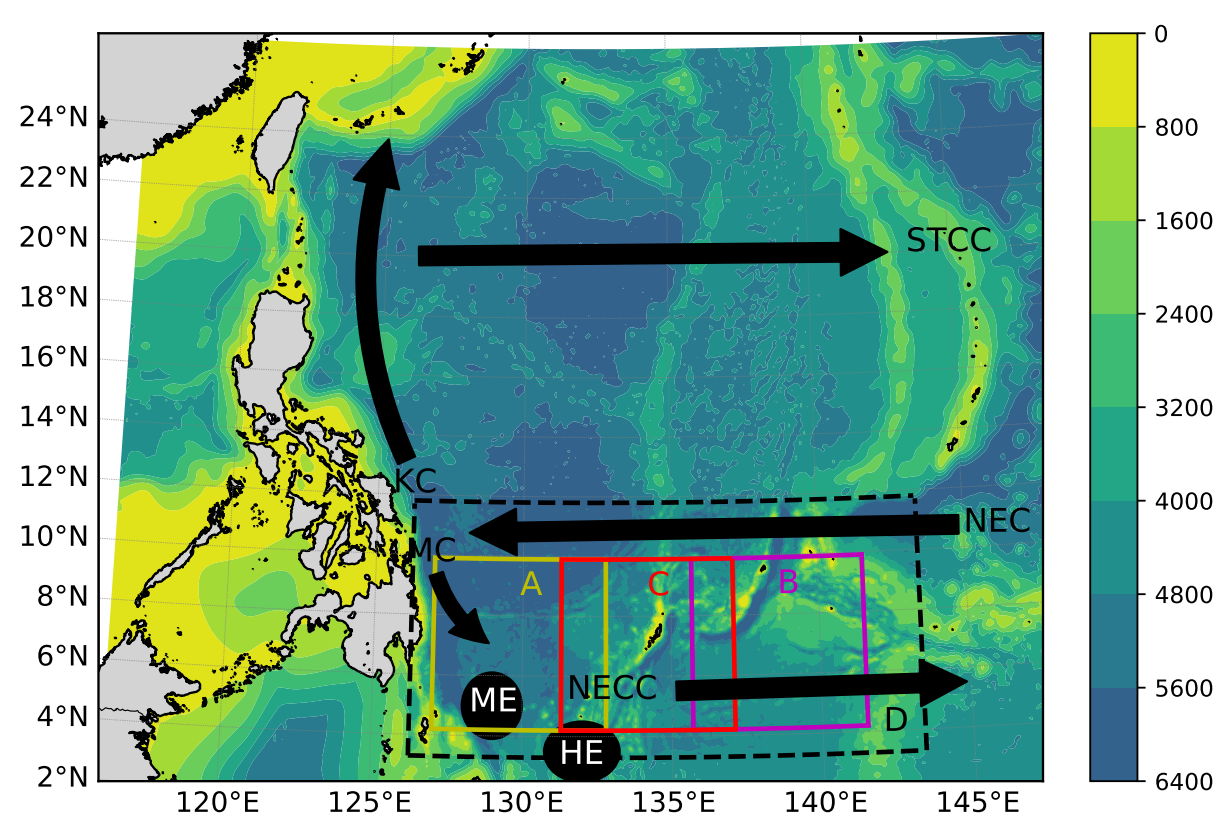

FIGURE 1. Bottom depth with schematic of major currents in the region. The Subtropical Countercurrent (STCC), North Equatorial Current (NEC), North Equatorial Countercurrent (NECC), Mindanao Current (MC), Kuroshio (KC), Mindanao Eddy (ME), and Halmahera Eddy (HE) are indicated by arrows or ellipses. The boundaries of the $2.5 \mathrm{~km}$ model domain are marked with dashed black lines and labeled as Region D. The boundaries of the three square domains $(640 \mathrm{~km}$ on a side) used for calculation of the spectral energy flux are marked by yellow (Box A), magenta (Box $B)$, and red (Box C) colored lines. et al., 2013; Pouquet and Marino, 2013; Bühler et al., 2014; Brüggemann and Eden, 2015; Marino et al., 2015). None of these studies were conducted with variable bottom topography, although Scott and Wang (2005) discuss the possibility that islands arrest the barotropization process that fuels the inverse cascade. We can then hypothesize that the theory supports the possibility of simultaneous inverse and forward kinetic energy cascades in the WTP surface.

To characterize the energy transfer in the western tropical Pacific, we diagnose several aspects of the surface velocity field in a regional $8 \mathrm{~km}$ horizontal resolution state estimation and a submesoscaleresolving $2.5 \mathrm{~km}$ nested forward model within it, including calculation of the spectral energy flux at the surface, where mesoscale dynamics have been shown to be representative of dynamics at greater depths in the presence of rough topography (LaCasce, 2017; Trossman et al., 2017).

\section{MODEL BACKGROUND}

The Regional Ocean Model System (ROMS) is used together with a version of four-dimensional Physical-space Statistical Analysis System (Courtier, 1997) to create an $8 \mathrm{~km}$ resolution state estimate of the western tropical Pacific for the 2014-2017 time period (henceforward the $8 \mathrm{~km}$ model). A $2.5 \mathrm{~km}$ resolution forward model (the $2.5 \mathrm{~km}$ model) is nested within it. ROMS is a terrainfollowing, hydrostatic, and Boussinesq three-dimensional model of the primitive Reynolds-averaged Navier-Stokes equations (Shchepetkin and McWilliams, 2005, 2008). Both models are implemented with a free surface in spherical coordinates, tidal forcing, and the K-Profile Parameterization (KPP) turbulence closure model (Large et al., 1994).

Figure 1 shows the domain for the models. The $8 \mathrm{~km}$ model uses lateral boundary conditions from the global Navy Coupled Ocean Data Assimilation (Bleck 2002; Cummings 2005). Barotropic tidal forcing is prescribed using TOPEX/ Poseidon global inverse solutions (Egbert 
and Erofeeva, 2002). Atmospheric forcing comes from the National Centers for Environmental Prediction Global Forecasting System (Kistler et al., 2001). The $8 \mathrm{~km}$ state estimate is generated through making adjustments to the initial conditions, atmospheric surface forcing, and lateral boundary conditions in an iterative minimization procedure, with the goal of reducing a global model data residual function, that is normalized by the parameter-dependent expected variances. The data assimilation window length is seven days.

The $2.5 \mathrm{~km}$ model (region $\mathrm{D}$ in Figure 1) is offline nested within the output of the $8 \mathrm{~km}$ state estimate. The remotely generated barotropic and baroclinic tides (e.g., from the Luzon Strait) in the $8 \mathrm{~km}$ model are spectrally propagated into the domain from their application at the lateral boundaries (Janekovic and Powell, 2012). The model also resolves local baroclinic tides that are generated within the domain (e.g., through interaction with steep topography).

\section{WESTERN TROPICAL PACIFIC REANALYSIS (8 KM MODEL)}

\section{Assimilated Data}

Assimilated data in the $8 \mathrm{~km}$ model include satellite measurements of sea surface temperature, sea surface height anomaly, and sea surface salinity as well as in situ measurements of temperature, salinity, and east and north velocity components from a combination of moorings, gliders, and floats. Daily $10 \mathrm{~km}$ resolution sea surface temperature maps are obtained from the Naval Oceanographic Office (NAVO) blended product, which combines data from three orbiting and two geostationary satellites (May et al., 1998). Sea surface salinity is assimilated from maps of the NASA Aquarius satellite. Satellitebased estimates of along-track sea surface height anomalies are from AVISO. Before assimilation, we add the mean sea surface height as obtained from a companion forward model that is initialized and forced identical to the $8 \mathrm{~km}$ model. We also add tides to the sea surface height anomaly values. The average number of observations and their standard deviations in a seven-day period are $240,667 \pm 33,313$ for NAVO, 28,907 $\pm 5,282$ for AVISO, and $1,151 \pm 46$ for Aquarius satellites.

Observations of temperature, salinity, and horizontal current components come from two TOGA-TAO Array moorings at $8^{\circ} \mathrm{N}, 137^{\circ} \mathrm{E}$ and $5^{\circ} \mathrm{N}, 137^{\circ} \mathrm{E}$ (McPhaden, 1995). Twenty-minute (temperature/ salinity) or hourly (currents) data are low-pass filtered at six-hour intervals, then subsampled every two hours, before assimilation. Temperature and salinity profiles to $1,000 \mathrm{~m}$ depth are retrieved from repeated underwater glider sections on either side of the Palau ridge at $134.25^{\circ} \mathrm{E}$ and $135^{\circ} \mathrm{E}$ between $7.75^{\circ} \mathrm{N}$ and $9^{\circ} \mathrm{N}$. Temperature and salinity profiles are assimilated from the Argo Program array of approximately 3,000 floats that profile between the surface and 2,000 m every 10 days (Oka and Ando, 2004). The average numbers of in situ observations for both temperature and salinity in a sevenday period (and percentage of time the data are available) are 8,642 $\pm 3004(65 \%)$ for the gliders, $4,292 \pm 1,415$ (100\%) for Argo, and 4,416 $\pm 2,319$ (79\%) for the two TOGA-TAO moorings. For velocity component data from the TOGA-TAO moorings, the corresponding statistics are $194 \pm 61$ (66\%).

The normalization variances for the different types of data are calculated separately. For the NAVO sea surface temperature observations, space/time dependent variances are provided by the US Navy. We use a constant standard deviation of $0.04 \mathrm{ppt}$ (parts per thousand) for Aquarius sea surface salinity. The AVISO sea surface height anomaly standard deviation is either $5 \mathrm{~cm}$ or $7 \mathrm{~cm}$, depending on the satellite. For the depth-dependent mooring, glider, and Argo observations, we calculate the mean variance for a selection of moorings in the tropical and subtropical Pacific, as well as the glider data in our domain; these data are binned by depth after removal of the time and depth bin mean for each seven-day interval, then averaged over the entire time period.

\section{Assimilation Results}

On average, the cost function that measures the residual between the model and the observations is reduced by $50 \%$ in the analysis step after 13 iterations of the minimization procedure. Two independent measures of how well the model is approximating the data are: (1) the rootmean-square anomalies (RMSA) between the model and the data, and (2) the cross correlations of the observed to modeled anomalies (ACC), calculated as the mean cross correlation between the observations and their post-assimilation model counterparts over the period of one day. The former is a bulk measure of how well the model represents the observed values, and the latter is a measure of how well the model represents the observed patterns.

Figure 2a,b shows the 2014-2017 mean RMSA for NAVO sea surface temperature for the forecast (i.e., model output pre-assimilation) and for the analysis (post-assimilation) step of the calculation. The largest biases between the model and the data are in the region of the STCC, which supports a vigorous eddy field (Qiu, 1999; Qiu and Chen, 2010). This is likely because the model does not track the phasing of the westward-propagating eddies. With assimilation of all the variables, the phasing error and the RMSA in this latitude range (approximately north of $20^{\circ} \mathrm{N}$ ) are both reduced. The spatially averaged temperature RMSA presented as a function of time (Figure $2 \mathrm{c}$ ) varies between $0.2^{\circ} \mathrm{C}$ and $1.5^{\circ} \mathrm{C}$ during the forecast step. The sporadic, very large excursions that last five to 10 days (e.g., in July of 2015) occur during the passages of hurricanes and tropical storms. Similar results are achieved for AVISO. The assimilation of Aquarius measurements did not significantly reduce the modeldata misfit for sea surface salinity.

The in situ measurements show that the model well represents the variability of the temperature as a function of depth (not shown). The vertical structure of the residuals mirrors that of the temperature profile itself, with the largest RMSA in the main thermocline between 
approximately $100 \mathrm{~m}$ and $200 \mathrm{~m}$ depth. The largest improvements in RMSA and ACC are in the thermocline for all of the in situ measurements.

The salinity profiles are not as well represented in the model as temperature, and this has implications for the water mass properties in the model, which could alter some dynamics. The Argo salinity ranges include some locations where the salinity is much lower than in the model between $400 \mathrm{~m}$ and $100 \mathrm{~m}$, and the reduction in RMSA (increase in ACC), when averaged over space, is confined to the upper $200 \mathrm{~m}$ of water (not shown).

\section{ANALYSIS TOOLS}

We examine the surface layers of the models using two different metrics for the energy present: (1) the spectral density of kinetic energy, and (2) the spectral energy flux. All of the analyses' metrics are computed for Region D of Figure 1. Because of the spatially variable bottom depth and challenges with interpolation from terrain-following depth sur- faces (i.e., $\sigma$ coordinate model) to constant depth levels, we have restricted our analyses to the surface layer, which has a nominal depth of $2.5 \pm 0.2 \mathrm{~m}$.

\section{Spectral Density of Kinetic Energy}

The spectral density of the kinetic energy,

$$
\Gamma_{K E}(t)=\frac{1}{2 H \Delta k} \int_{H}^{0} \hat{\mathbf{u}}^{\prime \star} \cdot \hat{\mathbf{u}}^{\prime} d z,
$$

is calculated at each time step (and then averaged over the indicated time period), following Brüggemann and Eden (2015), where $H=2.5 \mathrm{~m}$ is the average depth of the surface layer, $\Delta k$ is the total horizontal wavenumber increment, and $\mathbf{u}^{\prime}$ is the vector of horizontal velocity components for the surface layer relative to the time mean (for the 2014-2017 period). The term $\hat{\mathbf{u}}^{\prime}$ designates that a discrete twodimensional Fourier transform has been applied in space, and * indicates the complex conjugate. There is an implied azimuthal integration to convert the twodimensional spectral density into a one-dimensional radial profile.
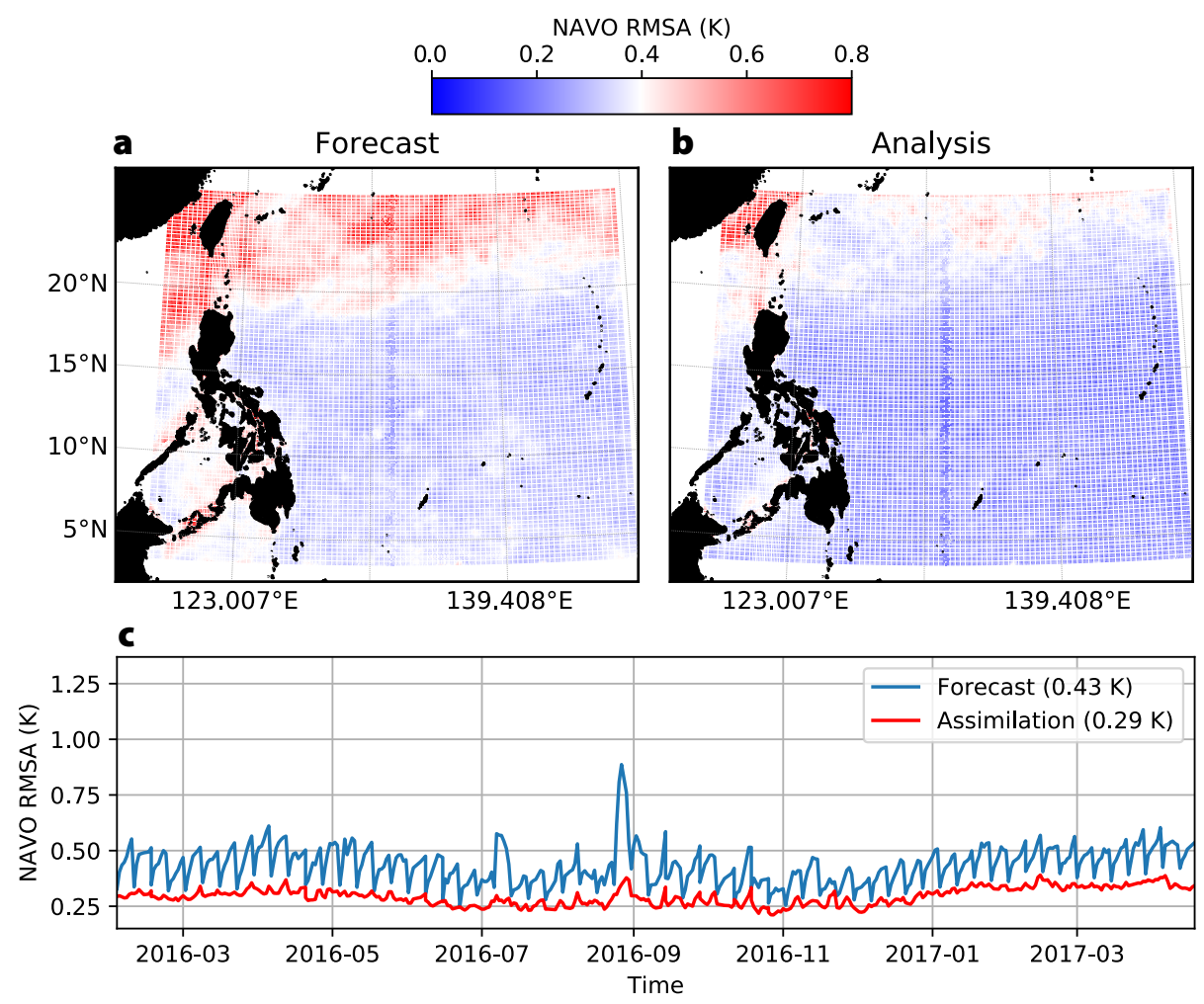

FIGURE 2. Naval Oceanographic Office (NAVO) sea surface temperature root-mean-square anomalies (RMSA) for the $8 \mathrm{~km}$ model state estimate of the western tropical Pacific for the 2014-2017 time period. (a) Spatial map, forecast step. (b) Spatial map, analysis step. (c) Spatially averaged time series of RMSA.

\section{Spectral Energy Flux}

The horizontal component of the spectral energy flux, $\Pi(K)$, is calculated separately at each time step based on the equations presented in Capet et al. (2008b):

$\Pi(K)=\int_{s=K}^{s=K_{h i}} \int_{0}^{2 \pi}{\hat{\mathbf{u}^{\prime}}}^{\star} \cdot\left(\widehat{\mathbf{u}^{\prime} \cdot \nabla \mathbf{u}^{\prime}}\right) s d \theta d s$,

where $K$ is the total horizontal wavenumber with $K_{h i}=1 / 4 \delta_{x}, \theta$ is the azimuthal angle, and $\delta_{x}$ is the grid cell length. $K_{h i}$ is highest total wavenumber we expect to be resolved by the model, instead of the Nyquist wavenumber. Note that we intentionally omit calculation of the vertical component of Equation 2 as our intent is to describe the horizontal transfer of energy. The advection is calculated from the surface layer of horizontal velocity (relative to the time mean for the 20142017 period), which is prone to noise. All of the derivatives in this equation are based on fourth-order finite difference equations, which are combined in wavenumber space. To reduce artificial discontinuities in the derivatives, the land values are replaced with a two-dimensional spatial linear average of neighboring water pixels prior to differentiation. However, after removal of the spatial mean, the land pixels are reset to zero. (Note here that the fraction of the number of land pixels to the total number of pixels in our domain is $0.5 \%$.) The resulting processed twodimensional velocity anomaly and advection of momentum fields were multiplied by a Hamming window before application of a two-dimensional Fourier transform. The spectral terms were linearly combined to calculate the integrand of Equation 2, which was then integrated in wavenumber space to calculate $\Pi(k)$. At each three-hourly time step, the spectral energy flux was calculated for the three square subdomains of approximately $640 \mathrm{~km} \times 640 \mathrm{~km}$ on a side (Boxes A-C in Figure 1), which were then linearly averaged. We subsampled the spectral energy time series at the (calculated) seven-day complex velocity anomaly decorrelation period (defined as the timescale corresponding to an average cross correlation of 0.5 ) before averaging in time. 
For long-term averages in time, the sign of $\Pi(K)$ indicates the direction of the energy transfer, with negative values corresponding to an inverse cascade toward longer length scales and positive values corresponding to a forward cascade toward shorter length scales (Scott and Wang, 2005). In that case, the slope of $\Pi(K)$ suggests whether there is a source (positive value) or sink (negative value) of kinetic energy as a function of wavelength.

\section{MEAN DYNAMICAL CONDITIONS}

All of our analyses are calculated for the region containing the NEC and the NECC (Region D of Figure 1). The spectral energy transfer at latitudes north of $15^{\circ} \mathrm{N}$ is described elsewhere (Scott and Wang, 2005).The surface layer of the western tropical Pacific is characterized by strong stratification (Froude numbers Fr of 0.02-0.03), moderately nonlinear flow with slow rotation (Rossby number, Ro, in 0.3-1.5 range) and a large internal waveguide ( $N / f$ between 10 and 30 , where $N$ is the BruntVäisälä buoyancy frequency, and $f$ is the Coriolis parameter). This places the dynamical regime somewhere in between those considered by Marino et al. (2015) and Brüggemann and Eden (2015). The time-averaged spectral density of kinetic energy $\left(\Gamma_{K E}\right)$ for the El Niño (20142015) period in the $2.5 \mathrm{~km}$ model (Figure 3 ) as calculated for Region D of Figure 1 shows that there is more variance in the kinetic energy at all wavenumbers. This result is similar to what Kjellsson and Zanna (2017) found in global models and raises the possibility that the barotropization process is weaker in the $8 \mathrm{~km}$ model, resulting in a more baroclinic flow with reduced conversion of energy from potential to kinetic.

In the $10-160 \mathrm{~km} / \mathrm{cycle}$ length scale range, the slope of the energy spectrum is close to -2 , and for scales larger than $160 \mathrm{~km} / \mathrm{cycle}$, the slope is closer to -1 . A similar shape is observed in the $8 \mathrm{~km}$ model, but the wavelength about which the slope changes magnitude shifts to around $500 \mathrm{~km} / \mathrm{cycle}$, and more particularly, the slope at scales smaller than that is -2.5 . The flattening of the slope from -2.5 to -2 upon grid refinement is expected as a result of better resolution of submesoscale features, which can be much larger in the tropics than at midlatitudes (Marchesiello et al., 2011). For the JanuarySeptember 2015 time period, there are also proportionately fewer points with low relative vorticity (i.e., in the $[-0.15 f, 0.15 f]$ range), and more points with large relative vorticity (i.e., outside of that range) in the $2.5 \mathrm{~km}$ model than in the $8 \mathrm{~km}$ model (compare panels a and $\mathrm{b}$ in Figure 4; see also Figure 5a). The mean spatial distributions of positive and negative relative vorticity in the $2.5 \mathrm{~km}$ model are asymmetrical (Figure $5 \mathrm{~b}$ ), consistent with observations (Rudnick, 2001; Shcherbina et al.,

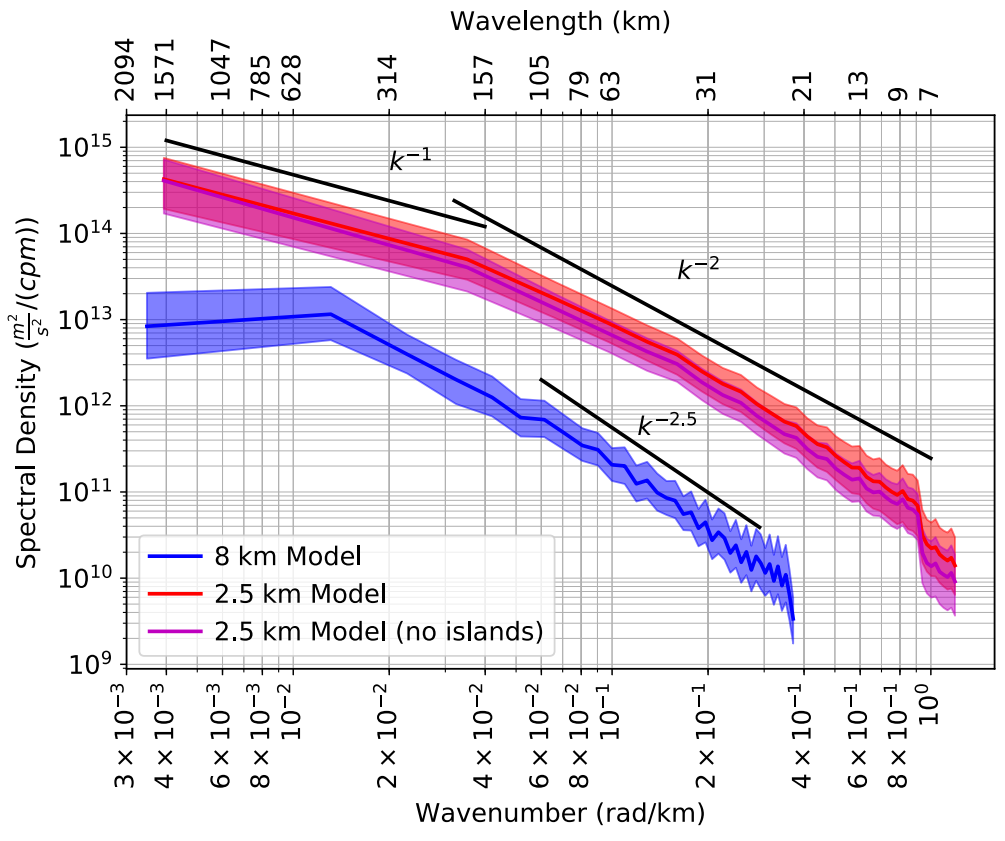

FIGURE 3. Mean El Niño (2014-2015) spectral density function of east and north velocity surface currents for the $2.5 \mathrm{~km}$ and $8 \mathrm{~km}$ models (calculated for Region D in Figure 1). The 95\% confidence intervals are shown for each curve with black lines, and the slopes of the curves in wavenumber space are indicated in black text.
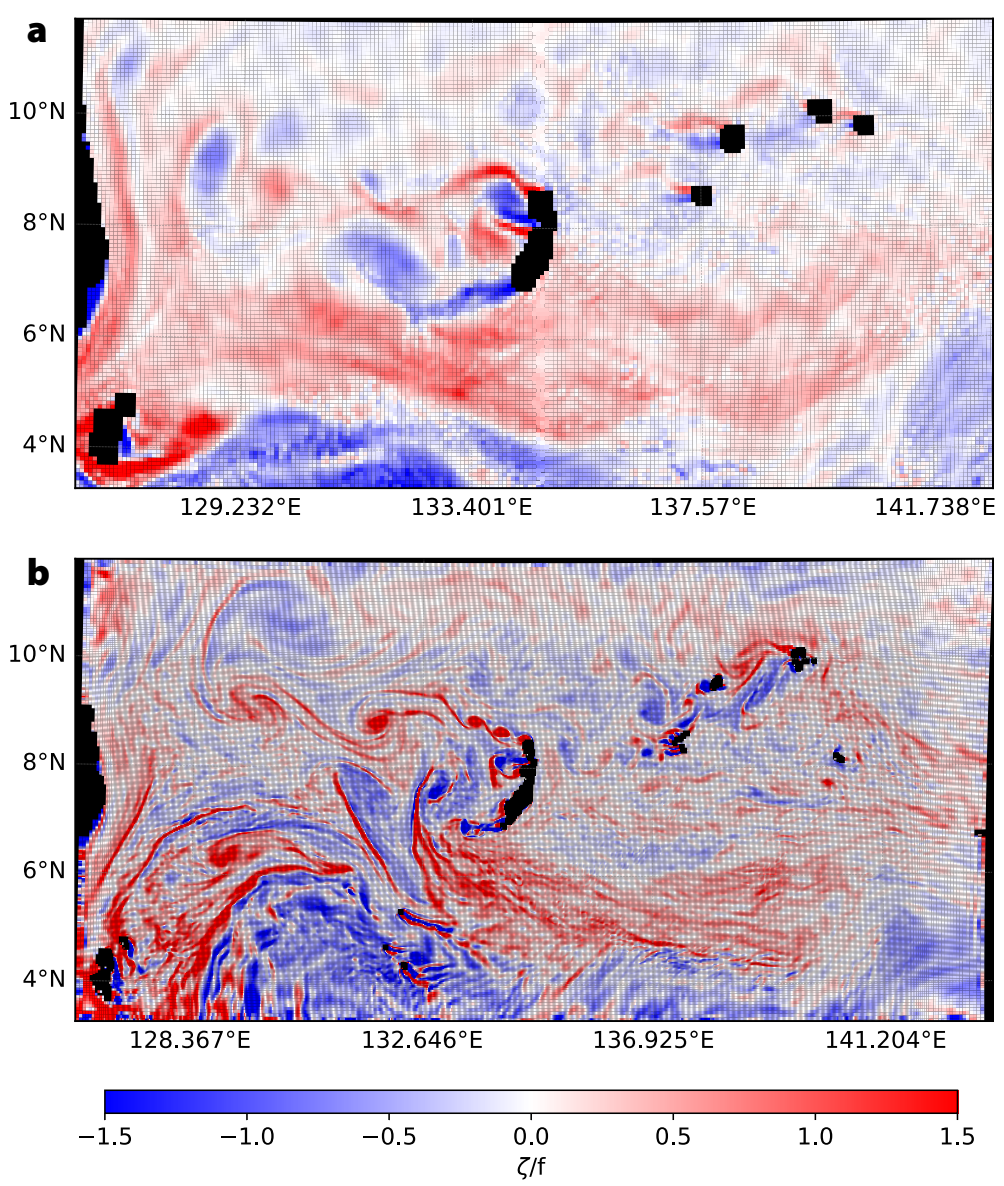

FIGURE 4. Snapshots of surface relative vorticity normalized by the Coriolis parameter $(f)$ on January 16, 2015, for (a) the $8 \mathrm{~km}$ model, and (b) the $2.5 \mathrm{~km}$ model. 
2013) and models (Capet et al., 2008a; Roullet and Klein, 2010; Klein et al., 2011). The skewness is $0.25 \pm 0.18$ for the $2.5 \mathrm{~km}$ model, characteristic of a longer tail for $\zeta>0$, whereas it is statistically indistinguishable from zero in the $8 \mathrm{~km}$ model $(-0.07 \pm 0.16)$. Although the skewness is smaller than found in Capet et al. (2008a) (1.3 for the California Current) and Shcherbina et al. (2013) (2.5 for the North Atlantic mode water production a Mean PDF of $\zeta / f(J a n-S e p ~ 2015)$

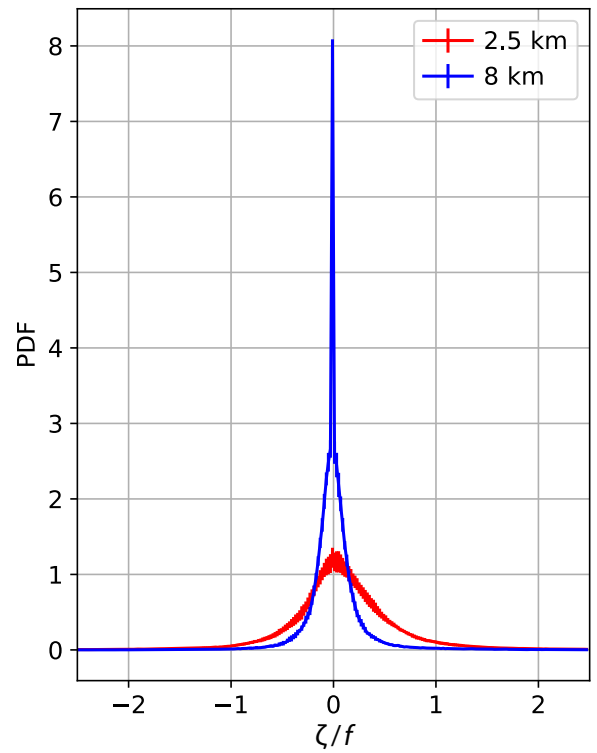

region in winter), the WTP has a relatively shallow mixed layer and a strongly stratified pycnocline that could suppress submesoscale vorticity. Without creating a finer resolution model, we cannot determine whether the $2.5 \mathrm{~km}$ model is merely submesoscale permitting or submesoscale resolving. We can say with certainty that the $2.5 \mathrm{~km}$ model resolves at least some submesoscale features and that it plays a role in broadening the spread of

\section{b $\quad 2.5 \mathrm{~km}$ : PDF of $\mathrm{ABS}(\zeta / f)$}

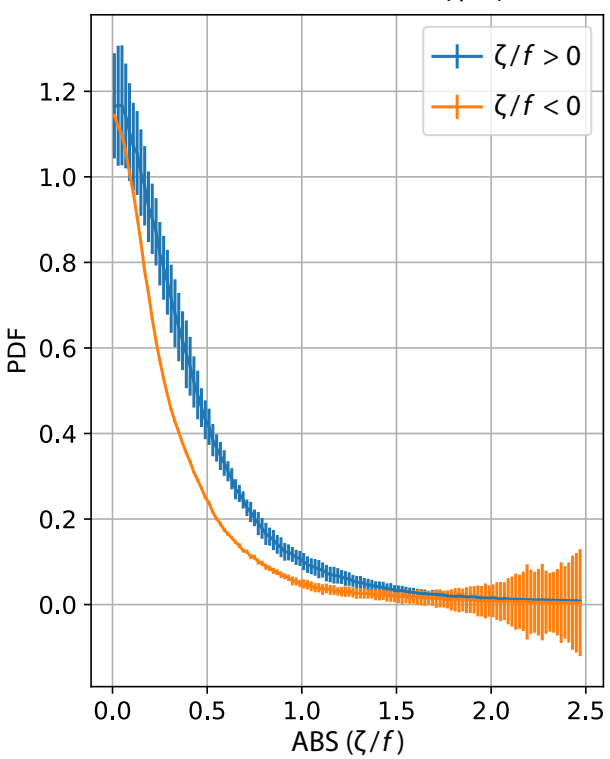

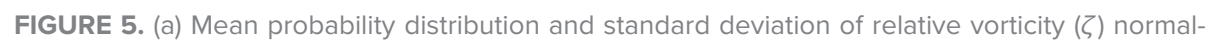
ized by the Coriolis parameter $(f)$ for the $2.5 \mathrm{~km}$ model domain for the January-September 2015 time period. Prior to averaging and calculation of the standard deviation, the probability density function (PDF) is subsampled every 28 days (the mean decorrelation time for kinetic energy for the domain after the time mean is removed), resulting in nine records, shown for both the $2.5 \mathrm{~km}$ and the $8 \mathrm{~km}$ models. (b) Relative vorticity for $2.5 \mathrm{~km}$ model shown as a function of absolute value of $\zeta$.

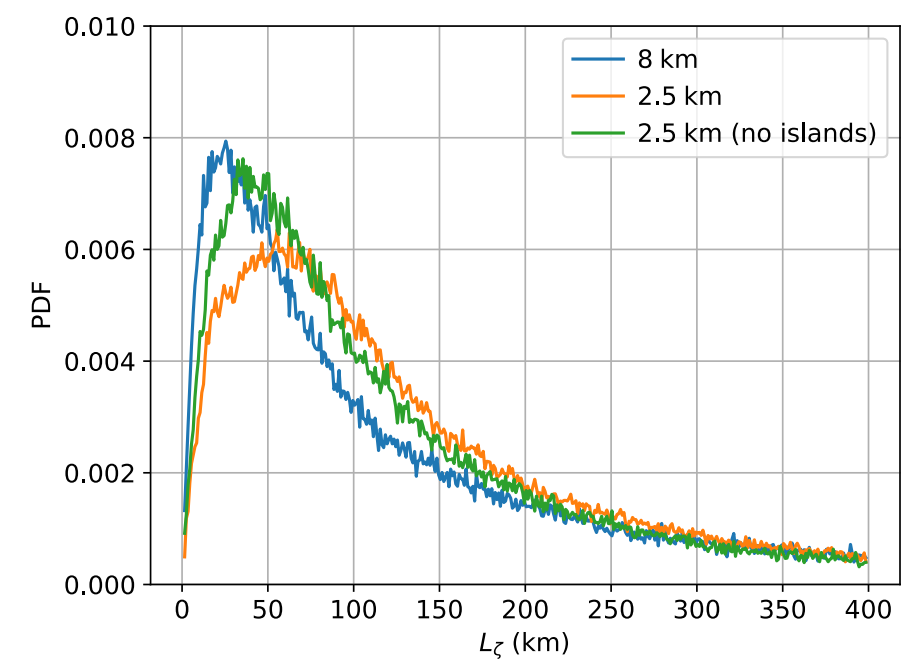

FIGURE 6. Snapshot of probability distribution of length scales in kilometers on January 16, 2015, in $8 \mathrm{~km}$ and $2.5 \mathrm{~km}$ models for Region D of Figure 1. surface $\zeta$ toward higher values.

Assuming that the surface current speed is oriented along an unstable front, length scales can be assigned to the relative vorticity $\left(L_{\zeta}=S / \zeta\right)$ where $S$ and $\zeta$ are the pointwise current speed and relative vorticity, respectively, at a given time. As an example, Figure 6 shows the distribution of surface length scales from a snapshot on January 16, 2015, during the height of the El Niño period for both models. This illustrates that the length scale distributions in the $2.5 \mathrm{~km}$ and $8 \mathrm{~km}$ models differ roughly over the $0-200 \mathrm{~km}$ range, with a larger fraction of points at length scales between $35 \mathrm{~km}$ and $200 \mathrm{~km}$ in the $2.5 \mathrm{~km}$ model than in the $8 \mathrm{~km}$ model, which is approximately the range of island diameters (Palau has a diameter of $200 \mathrm{~km}$ ). It is also clear from Figure $4 \mathrm{~b}$ that lateral gradients of $\zeta$ in the $2.5 \mathrm{~km}$ model are stronger in the vicinity of the island wakes.

\section{DYNAMICS}

The 2014-2017 time period spans two distinct physical regimes. In 2014, the El Niño phase began with a shoaling of the thermocline in the western Pacific, but it pauses (though the northwestern Pacific remained in an El Niño phase) until 2015 with the full El Niño. In 2016, the sea surface height is restored and there is a transition to normal conditions during and after the arrival of several Rossby waves. In this section, we discuss the energy transfer for the El Niño 2014-2015 period (technically, February 2014-January 2016).

\section{Energy Transfer}

During both the El Niño (2014-2015) and the transition (2016) periods, the spectral energy flux is highly variable in time, consistent with previous studies (Scott and Wang, 2005). The El Niño mean spectral energy flux indicates that there are simultaneous dual cascades to larger and smaller scales in both models (Figure 7). The spectral energy flux profiles in the $8 \mathrm{~km}$ and $2.5 \mathrm{~km}$ models show that there is energy input at scales of around $200 \mathrm{~km} / \mathrm{cycle}$, a range that overlaps with that of the first baroclinic Rossby 
deformation radius in the region (Emery et al., 1984; Chelton et al., 1998) as well as the Rhines $\beta$-scale (Rhines, 1975) and generalized Rhines $\beta$-scale to account for stratification (Theiss, 2006). This suggests that the horizontal component of energy transfer in the western tropical Pacific behaves much like the energy transfer at higher latitudes and supports the theory (as discussed in Scott and Wang, 2005) that there is a source of energy near the baroclinic Rossby radius of deformation. The theory states that energy transfers upscale to the first mode, where it transfers to even larger scales during barotropization. The strength of the inverse cascade is greater in the $2.5 \mathrm{~km}$ than in the $8 \mathrm{~km}$ model. In the $80 \mathrm{~km} /$ cycle $-160 \mathrm{~km} /$ cycle range, the horizontal component of the spectral energy flux is of about the same magnitude in both models. It is worth noting that the forward cascade is slightly stronger in the $2.5 \mathrm{~km}$ model in the $30-70 \mathrm{~km} /$ cycle length scale range, which overlaps with the range of island scales, as well as the range where $L_{\zeta}$ is larger in the $2.5 \mathrm{~km}$ than in the $8 \mathrm{~km}$ model.

\section{Islands}

To disentangle the effects of the islands on the energy transfer from submesoscale energy transfer, we create a version of the $2.5 \mathrm{~km}$ model where we have replaced all topography shallower than $2 \mathrm{~km}$ with a value of $2 \mathrm{~km}$, removing all islands and seamounts from the interior of the domain while retaining the spatial variability in original topography below $2 \mathrm{~km}$ (i.e., all shallow topography in the interior has been shaved off). This $2.5 \mathrm{~km}$ no-islands model, however, still includes the island of Mindanao on the western boundary, which is important for getting the canonical circulation in the WTP right. The El Niño (2014-2015) kinetic energy spectrum for the $2.5 \mathrm{~km}$ no-islands model is statistically indistinguishable from that for the $2.5 \mathrm{~km}$ model, although the mean spectrum for the $2.5 \mathrm{~km}$ model is slightly higher at all wavelengths (Figure 3 ). This suggests that the characteristics of the energy transfer might also be similar.
However, as Figure 7 shows, they differ. The horizontal component of the inverse and forward cascades for the surface layer are about twice as strong in the presence of islands. Without calculating further diagnostics that extend below the pycnocline, we cannot definitively identify the types of instabilities responsible for this difference. However, the $2.5 \mathrm{~km}$ model is at least submesoscale permitting; the submesoscale can be ageostrophic (Capet et al., 2008b), and ageostrophic flow has a forward cascade of kinetic energy (Brüggemann and Eden, 2015).

To summarize, the net effect of the islands during an El Niño year, as diagnosed from an evaluation of surface flows, is that the islands enhance the strength of the horizontal component of both the inverse and the forward kinetic energy cascades. The forward cascade is likely boosted through the creation of smaller scales as the tides and currents interact with the topography. The facts that the eddy energy budgets (for the surface layer, not shown) and the magnitude of the inverse cascade are strongest and largest in the $2.5 \mathrm{~km}$ model suggest that resolving rough topography, in addi-

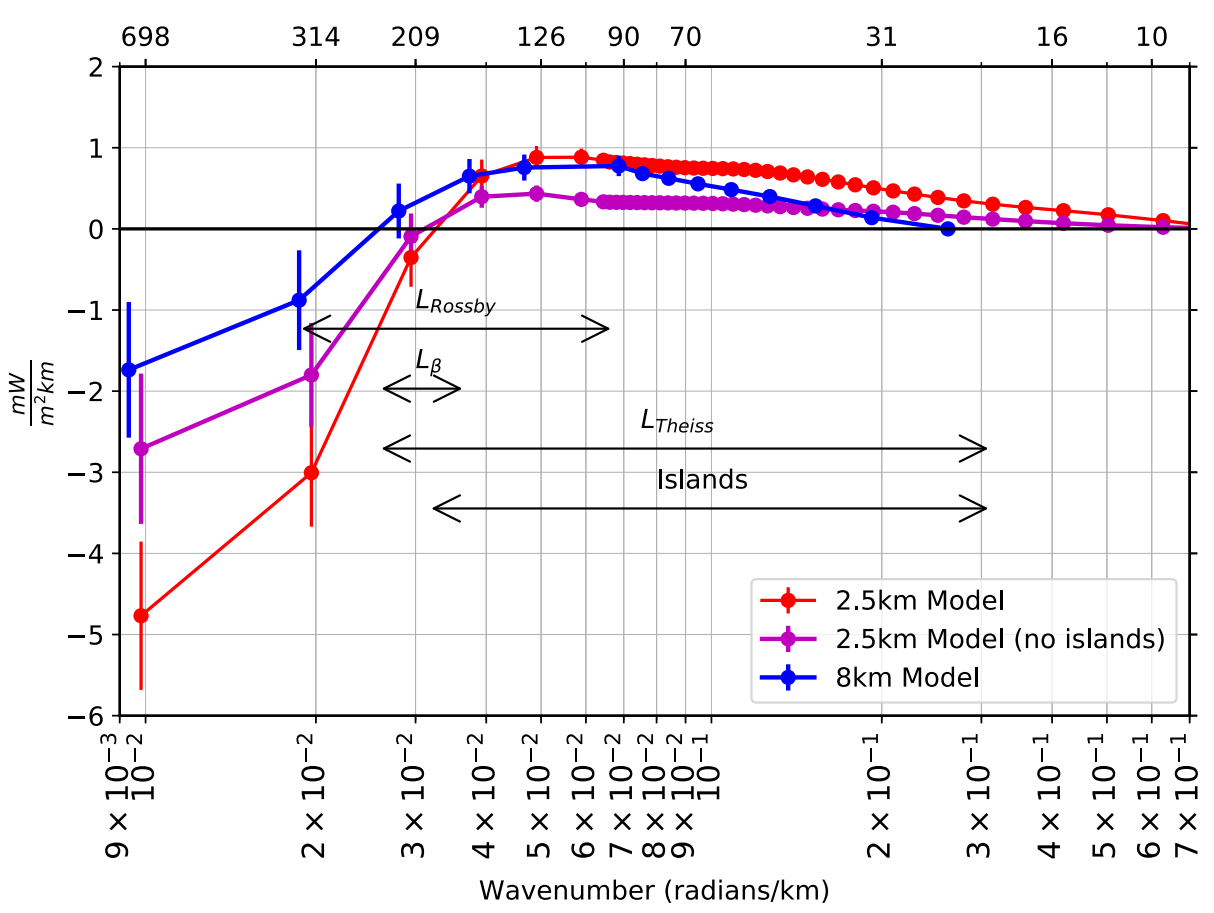

FIGURE 7. Time-averaged El Niño (2014-2015) spectral energy flux for $2.5 \mathrm{~km}$ and $8 \mathrm{~km}$ models, averaged over Regions A, B, and C from Figure 1. tion to the submesoscale, is important for getting the energetics right. Whether this result holds up for a three-dimensional calculation of the total spectral energy flux is left for future work. Here, we can point out that our results are valid when the horizontal part of the spectral energy flux is calculated for a $100 \mathrm{~m}$ thick, vertically averaged velocity layer, for the same time interval (not shown). As a function of time, the variability in the spectral energy flux during the El Niño (20142015 ) is similar in the two models, with a correlation coefficient of about 0.5 at $800 \mathrm{~km} /$ cycle. Where the spectral energy fluxes differ most is in 2016, during the transition back to near normal conditions, as discussed in the next section.

\section{DISCUSSION AND CONCLUDING REMARKS}

Despite unique dynamical conditions, energy transfer in the western tropical Pacific behaves similarly to that in the extratropics (Scott and Wang, 2005; Capet et al., 2008b), with an inverse cascade at scales overlapping with the first baroclinic Rossby deformation radius to the basin scale, and a weaker forward 
cascade from $L_{\text {Rossby }}$ toward dissipation. The kinetic energy source for the inverse cascade is the dynamics at $L_{\text {Rossby }}$. The strength of surface kinetic energy cascades varies considerably on interannual timescales. Through comparison with a model that has no topography above 2,000 $\mathrm{m}$, we were able to show that the presence of the steep, variable topography also modifies the strength of surface kinetic energy cascades. Relative to the companion $2.5 \mathrm{~km}$ no- islands model, the strengths of both the inverse and the forward cascades in the $2.5 \mathrm{~km}$ model with topography are roughly doubled, while at the same time, the distributions of normalized surface relative vorticity are roughly the same in both models.

The asymmetrical distribution of surface relative vorticity in the $2.5 \mathrm{~km}$ model with topography, with a skewness of $0.25 \pm 0.18$ (more large positive than large negative relative vorticity), suggests that there is an ageostrophic (i.e., divergent) component of the flow, which is typically associated with frontogenesis and a forward cascade of kinetic energy (Roullet and Klein, 2010). Nevertheless, the distributions of normalized relative vorticity are approximately the same in both the $2.5 \mathrm{~km}$ and $2.5 \mathrm{~km}$ no-islands models. However, the peak of the surface current speed distribution (e.g., on January 16, 2015, not shown) shifts slightly toward lower values in the $2.5 \mathrm{~km}$ no-islands case. This changes the peak of the distribution of associated (maximum) length scales, which depends on their ratio, in the $2.5 \mathrm{~km}$ no-islands model toward smaller values. The zero crossing point of about $300 \mathrm{~km} /$ cycle that separates the inverse and forward cascades is unchanged in both the no-islands and islands cases. This contradicts the hypothesis discussed in Scott and Wang (2005) that the islands interrupt the barotropization process that shortens this length scale. It is possible that the islands need to be larger in order to see this effect. The variable topography modifies energy transfer across scales in a similar way to that from the submesoscale. The fact that the islands do affect the character of energy trans- fer in the western tropical Pacific on long timescales suggests that they play a significant role on shorter timescales that are important for dynamical predictability.

Restricting our diagnoses to the surface layer limits our ability to interpret the full effects of the topography on the energy transfer. Depth-dependent diagnostics of an eddy energy budget and spectral energy flux terms would be helpful for diagnosing the relative strengths of baroclinic and barotropic instabilities. Development of a Fourier transform that can properly handle island discontinuities would be a huge contribution to the field. However, this is the first attempt to show the effect of realistic topography on energy transfer in the western tropical Pacific. We leave the development of a noise-minimizing method for calculating horizontal spectral energy fluxes at depth in a $\sigma$-coordinate model with variable bottom depth for future work. C

\section{REFERENCES}

Arbic, B., K. Polzin, R. Scott, J. Richman, and J. Shriver. 2013. On eddy viscosity, energy cascades, and the horizontal resolution of gridded satellite altimeter products. Journal of Physical Oceanography 43:283-300, https://doi.org/10.1175/ JPO-D-11-0240.1.

Arruda, W., and D. Nof. 2003. The Mindanao and Halmahera eddies: Twin eddies induced by nonlinearities. Journal of Physical Oceanography 33:2,815-2,830, https://doi.org/10.1175/15200485(2003)033<2815:TMAHEE>2.0.CO;2.

Bathen, K. 1972. On the seasonal changes in the depth of the mixed layer in the North Pacific Ocean. Journal of Geophysical Research 77:7,138-7,150, https://doi.org/10.1029/JC077i036p07138.

Bell, T. 1975. Topographically generated internal waves in the open ocean. Journal of Geophysical Research 80:320-327, https://doi.org/10.1029/ C080i003p00320.

Bleck, R. 2002. An oceanic general circulation mode framed in hybrid isopycnic-Cartesian coordinates. Ocean Modelling 4:55-88, https://doi.org/10.1016/ S1463-5003(01)00012-9.

Boccaletti, G., R. Ferrari, and B. Fox-Kemper. 2007. Mixed layer instabilities and restratification. Journal of Physical Oceanography 37:2,228-2,250, https://doi.org/10.1175/JPO3101.1.

Brüggemann, N., and C. Eden. 2015. Routes to dissipation under different dynamical conditions. Journal of Physical Oceanography 45:2,149-2,168, https://doi.org/10.1175/JPO-D-14-0205.1.

Bühler, O., J. Callies, and R. Ferrari. 2014. Wave-vortex decomposition of one-dimensional ship-track data. Journal of Fluid Mechanics 756:1,007-1,026, https://doi.org/10.1017/jfm.2014.488.

Callies, J., and R. Ferrari. 2013. Interpreting energy and tracer spectra of upper-ocean turbulence in the submesoscale range (1-200 km). Journal of Physical Oceanography 43:2,456-2,474, https://doi.org/10.1175/JPO-D-13-063.1.

Capet, X., J. McWilliams, M. Molemaker, and A. Shchepetkin. 2008a. Mesoscale to submesoscale transition in the California current system:
Part I: Flow structure, eddy flux, and observational tests. Journal of Physical Oceanography 38:29-43, https://doi.org/10.1175/2007JPO3671.1.

Capet, X., J. McWilliams, M. Molemaker, and A. Shchepetkin. 2008b. Mesoscale to submesoscale transition in the California Current System: Part III: Energy balance and flux. Journal of Physical Oceanography 38:2,256-2,269, https://doi.org/ 10.1175/2008JPO3810.1.

Chang, P. 1993. Seasonal cycle of sea surface temperature and mixed layer heat budget in the tropical Pacific Ocean. Geophysical Research Letters 20(19):2,079-2,082, https://doi.org/ 10.1029/93GL02374.

Chelton, D., R. DeSzoeke, M. Schlax, K. Naggar, and N. Siwertz. 1998. Geographic variability of the first baroclinic Rossby radius of deformation. Journal of Physical Oceanography 28:433-460, https://doi.org/10.1175/1520-0485(1998)028<0433: GVOTFB $>2.0 . C O ; 2$.

Courtier, P. 1997. Dual formulation of four-dimensional variational assimilation. Quarterly Journal of the Royal Meteorological Society B 75:2,449-2,461, https://doi.org/10.1002/qj.49712354414.

Cummings, J.A. 2005. Operational multivariate ocean data assimilation. Quarterly Journal of the Royal Meteorological Society 131(613):3,583-3,604, https://doi.org/10.1256/qj.05.105.

Dong, C., and J. McWilliams. 2007. A numerical study of island wakes in the Southern California Bight. Continental Shelf Research 27(9):1,233-1,248, https://doi.org/10.1016/j.csr.2007.01.016.

Egbert, G., and S. Erofeeva. 2002. Efficient inverse modeling of barotropic ocean tides. Journal of Atmospheric and Oceanic Technology 19:183-204, https://doi.org/10.1175/1520-0426(2002)019 $<0183$ :EIMOBO>2.0.CO;2.

Emery, W., W. Lee, and L. Magaard. 1984. Geographic and seasonal distributions of Brunt-Väisälä frequency and Rossby radii in the North Pacific and North Atlantic. Journal of Physical Oceanography 14:294-317, https://doi.org/10.1175/1520-0485(1984)014 $<0294$ :GASDOB>2.0.CO;2

Fu, L.-L., and G. Flierl. 1980. Nonlinear energy and enstrophy transfers in a realistically stratified ocean. Dynamics of Atmospheres and Oceans 4:219-246, https://doi.org/ 10.1016/0377-0265(80)90029-9.

Holloway, P., and M. Merrifield. 1999. Internal tide generation by seamounts, ridges, and islands. Journal of Geophysical Research 104(C11):25,937-25,951, https://doi.org/10.1029/1999JC900207.

Huppert, H., and K. Bryan. 1976. Topographically generated eddies. Deep-Sea Research and Oceanographic Abstracts 23:655-679, https://doi.org/10.1016/S0011-7471(76)80013-7.

Janekovic, I., and B. Powell. 2012. Analysis of imposing tidal dynamics to nested numerical models. Continental Shelf Research 34:30-40, https://doi.org/10.1016/j.csr.2011.11.017.

Johnson, E.S., L.A. Regier, and R.A. Knox. 1988. A study of geostrophy in tropical Pacific Ocean currents during the NORPAX Tahiti Shuttle using a shipboard Doppler acoustic current profiler. Journal of Physical Oceanography 18:708-723, https://doi.org/10.1175/1520-0485(1988)018<0708: ASOGIT>2.0.CO:2.

Johnson, G.C., B.M. Sloyan, W.S. Kessler, and K.E. McTaggert. 2002. Direct measurements of upper ocean currents and water properties across the tropical Pacific during the 1990s. Progress in Oceanography 52(1):31-61, https://doi.org/10.1016/ s0079-6611(02)00021-6.

Kashino, Y., N. Espana, F. Syamsudin, K. Richards, T. Jensen, P. Dutrieux, and A. Ishida. 2009. Observations of the North Equatorial Current, Mindanao Current, and Kuroshio current system during the 2006/07 El Niño and 2007/08 La Niña. Journal of Oceanography 65:325-333, https://doi.org/10.1007/s10872-009-0030-z.

Kistler, R., E. Kalnay, W. Collins, S. Saha, G. White, J. Woollen, M. Chelliah, W. Ebisuzaki, M. Kanamitsu, V. Kousky, and others. 2001. The NCEP- 
NCAR 50-year reanalysis: Monthly means CD-ROM and documentation. Bulletin of the American Meteorological Society 82:247-267, https://doi.org/10.1175/1520-0477(2001)082 0247:TNNYRM $>2.3 . \mathrm{CO} \cdot 2$

Kjellsson, J., and L. Zanna. 2017. The impact of horizontal resolution on energy transfers in global ocean models. Fluids 2(3):45, https://doi.org/ 10.3390/fluids2030045.

Klein, P., G. Lapeyre, G. Roullet, S. LeGentil, and H. Sasaki. 2011. Ocean turbulence at meso and submesoscales: Connection between surface and interior dynamics. Geophysical and Astrophysical Fluid Dynamics 105(4-5):421-437, https://doi.org/ 10.1080/03091929.2010.532498.

Kobashi, F., and A. Kubokawa. 2012. Review on North Pacific subtropical countercurrents and subtropical fronts: Role of mode waters in ocean circulation and climate. Journal of Oceanography 68(1):21-43, https://doi.org/10.1007/s10872-011-0083-7.

LaCasce, J.H. 2017. The prevalence of oceanic surface modes. Geophysical Research Letters 44:11,097-11,105, https://doi.org/ $101002 / 2017 \mathrm{GL} 075430$.

Lagerloef, G.S.E., G.T. Mitchum, R.B. Lukas, and P. Niiler. 1999. Tropical Pacific nearsurface currents estimated from altimeter wind, and drifter data. Journal of Geophysical Research 104(C10):23,313-23,326, https://doi.org/ 10.1029/1999JC900197.

Large, W.G., J.C. McWilliams, and S.C. Doney. 1994. Oceanic vertical mixing: A review and a model with a non-local boundary layer parameterization. Reviews of Geophysics 32:363-403, https://doi.org/10.1029/94RG01872.

Lindborg, E. 2006. The energy cascade in a strongly stratified fluid. Journal of Fluid Mechanics 550:207-242, https://doi.org/10.1017/ S0022112005008128.

Marchesiello, P., X. Capet, C. Menkes, and S. Kennan. 2011. Submesoscale dynamics in tropical instability waves. Ocean Modelling 39:31-46, https://doi.org/ 10.1016/j.ocemod.2011.04.011.

Marino, R., P. Mininni, D. Rosenberg, and A. Pouquet. 2013. Inverse cascades in rotating stratified turbulence: Fast growth of large scales. European Physical Letters 102(4), https://doi.org/10.1209/ 0295-5075/102/44006.

Marino, R., A. Pouquet, and D. Rosenberg. 2015. Resolving the paradox of oceanic large-scale balance and small-scale mixing. Physical Review Letters 114:114504, https://doi.org/10.1103/ PhysRevLett.114.114504.

May, D., M. Parmeter, D. Olszewski, and B. McKenzie. 1998. Operational processing of satellite sea surface temperature retrievals at the Naval Oceanographic Office. Bulletin of the American Meteorological Society 79(3):397-407, https://doi.org/10.1175/1520-0477(1998)079 $<0397$ :OPOSSS $>2.0 . \mathrm{CO} ; 2$.

McPhaden, M. 1995. The Tropical Atmosphere Ocean Array is completed. Bulletin of the American Meteorological Society 76:739-741, https://doi.org/ 10.1175/1520-0477-76.5.739.

Nikurashin, M., and R. Ferrari. 2010. Radiation and dissipation of internal waves generated by geostrophic motions impinging on smallscale topography: Theory. Journal of Physical Oceanography 40:1,055-1,074, https://doi.org/ 10.1175/2009.JPO4199.1.

Oka, E., and K. Ando. 2004. Stability of temperature and conductivity sensors of Argo profiling floats. Journal of Oceanography 60:253-258, https://doi.org/10.1023/B:JOCE.0000038331. 10108.79.

Philander, S., W. Hurlin, and A. Seigel. 1987. Simulation of the seasonal cycle of the tropical Pacific Ocean. Journal of Physical Oceanography 17(11):1,986-2,002, https://doi.org/ 10.1175/1520-0485(1987)017<1986:SOTSCO> 2.0.CO;2.

Pouquet, A., and R. Marino. 2013. Geophysical turbulence and the duality of the energy flow across scales. Physical Review Letters 111:234501, https://doi.org/10.1103/PhysRevLett.111.234501.
Qiu, B., and R. Lukas. 1996. Seasonal and interannual variability of the North Equatorial Current, the Mindanao Current, and the Kuroshio along the Pacific western boundary. Journal of Geophysical Research 101:12,315-12,330, https://doi.org/ 10.1029/95JC03204.

Qiu, B. 1999. Seasonal eddy field modulation of the North Pacific Subtropical Countercurrent: TOPEX/ Poseidon observations and theory. Journal of Physical Oceanography 29:2,471-2,486, https://doi.org/10.1175/1520-0485(1999)029 $<2471$ :SEFMOT>2.0.CO;2.

Qiu, B., and S. Chen. 2010. Interannual variability of the North Pacific subtropical counter current and its associated mesoscale eddy field Journal of Physical Oceanography 40:213-225, https://doi.org/10.1175/2009JP04285.1.

Qiu, B., T. Nakano, S. Chen, and P. Klein. 2017. Submesoscale transition from geostrophic flows to internal waves in the northwestern Pacific upper ocean. Nature Communications 8:14055, https://doi.org/10.1038/ncomms14055.

Qu, T., T. Chiang, C. Wu, P. Dutrieux, and D. Hu. 2012. Mindanao Current/Undercurrent in an eddyresolving GCM. Journal of Geophysical Research 117(C6), https://doi.org/10.1029/2011JC007838.

Reverdin, G., C. Frankingoul, E. Kestenare, and M. McPhaden. 1994. Seasonal variability in the surface currents of the equatorial Pacific. Journal of Geophysical Research 99(C10):20,323-20,344, https://doi.org/10.1029/94JC01477.

Reznik, G., and T. Tsybaneva. 1999. Planetary waves in a stratified ocean of variable depth: Part I. Two-layer model. Journal of Fluid Mechanics 388:115-145, https://doi.org/10.1017/ S0022112099004875.

Rhines, P., and F. Bretherton. 1973. Topographic Rossby waves in a rough-bottomed ocean. Journa of Fluid Mechanics 61:583-607, https://doi.org/ 10.1017/S002211207300087X

Rhines, P. 1975. Waves and turbulence on a betaplane. Journal of Fluid Mechanics 69:417-443, https://doi.org/10.1017/S0022112075001504.

Roullet, G., and P. Klein. 2010. Cyclone-anticyclone asymmetry in geophysical turbulence. Physical Review Letters 104:218501, https://doi.org/10.1103/ PhysRevLett.104.218501.

Rudnick, D. 2001. On the skewness of vorticity in the upper ocean. Geophysical Research Letters 28:2,045-2,048, https://doi.org/ 10.1029/2000GL012265.

Salmon, R. 1998. Lectures on Geophysical Fluid Dynamics. Oxford University Press, 378 pp.

Schönau, M., and D. Rudnick. 2015. Glider observations of the North Equatorial Current in the western tropical Pacific. Journal of Geophysical Research 120:3,586-3,606, https://doi.org/ 10.1002/2014JC010595.

Schönau, M., and D. Rudnick. 2017. Mindanao Current and Undercurrent: Thermohaline structure and transport from repeat glider observations. Journal of Physical Oceanography 47:2,055-2,075, https://doi.org/10.1175/JPO-D-16-0274.1.

Schott, F. 1977. On the energetics of baroclinic tides in the North Atlantic. Annual Reviews of Geophysics 33:41-62.

Scott, R., and F. Wang. 2005. Direct evidence of an oceanic inverse kinetic energy cascade from satellite altimetry. Journal of Physical Oceanography 45:1,650-1,666, https://doi.org/ 10.1175/JPO2771.1.

Shchepetkin, A., and J. McWilliams. 2005. The Regional Oceanic Modeling System (ROMS): A split-explicit, free-surface, topographyfollowing-coordinate oceanic model. Ocean Modelling 9:347-404, https:/doi.org/10.1016/ j.ocemod.2004.08.002

Shchepetkin, A., and J. McWilliams. 2008. Correction and commentary for "Ocean forecasting in terrain-following-coordinates: Formulation and skill assessment of the regional ocean modeling system." Journal of Computationa Physics 227:8,985-9,000, https:/doi.org/10.1016/ j.jcp.2009.09.002.
Shcherbina, A.Y., E. D’Asaro, C.M. Lee, J.M. Klymak, and M.J. Molemaker, and J.C. McWilliams. 2013. Statistics of vertical vorticity, divergence, and strain in a developed submesoscale turbulence field. Geophysical Research Letters 40:4,706-4,711, https://doi.org/10.1002/grl.50919.

Sverdrup, H. 1947. Wind-driven currents in a baroclinic ocean; with application to the equatorial currents of the eastern Pacific. Geophysics 33:318-326 https://doi.org/10.1073/pnas.33.11.318.

Theiss, J. 2006. A generalized Rhines effect and storms on Jupiter. Geophysical Research Letters 33, L08809, https://doi.org/10.1029/ 2005GL025379.

Trossman, D., B. Arbic, D. Straub, J. Richman, E. Chassignet, A. Wallcraft, and X. Xu. 2017. The role of rough topography in mediating impacts of bottom drag in eddying ocean circulation models. Journal of Physical Oceanography 47:1,941-1,958, https://doi.org/10.1175/JPO-D-16-0229.1.

Wang, F., Y. Li, and J. Wang. 2016. Intraseasonal variability of the surface zonal currents in the western tropical Pacific Ocean: Characteristics and mechanisms. Journal of Physical Oceanography 46:3,639-3,660, https://doi.org/10.1175/JPO-D-16-0033.1.

Wyrtki, K., and R. Kendall. 1967. Transports of the Pacific Equatorial Countercurrent. Journa of Geophysical Research 72(8):2,073-2,076 https://doi.org/10.1029/JZ072i008p02073.

Yu, Z., J.M. Jr., W. Kessler, and K. Kelly. 2000. Influence of equatorial dynamics on the Pacific North Equatorial Countercurrent. Journal of Physical Oceanography 30:3,179-3,190, https://doi.org/10.1175/1520-0485(2000)030 $<3179:$ IOEDOT>2.0.CO;2.

\section{ACKNOWLEDGMENTS}

Support was provided by the National Oceanographic Partnership Program and the Office of Naval Research by grants N00014-15-1-2600, N0014-15-12488, and N00014-15-1-2315 (B2). The altimeter products were produced by SSALTO/DUACS and distributed by AVISO, with support from CNES (http://www. aviso.altimetry.fr/duacs/). This is SOEST publication no. 10846

\section{AUTHORS}

Sarah E. Zedler (szedler@hawaii.edu) is Postdoctoral Research Fellow, Brian S. Powell is Professor, and Bo Qiu is Professor, all in the Department of Oceanography, University of Hawai'i at Mānoa, Honolulu, HI, USA. Daniel L. Rudnick is Professor, Scripps Institution of Oceanography, University of California San Diego, La Jolla, CA, USA.

\section{ARTICLE CITATION}

Zedler, S.E., B.S. Powell, B. Quu, and D.L. Rudnick. 2019. Energy transfer in the western tropical Pacific. Oceanography 32(4):136-145, https://doi.org/10.5670/ oceanog.2019.419.

\section{COPYRIGHT \& USAGE}

This is an open access article made available under the terms of the Creative Commons Attribution 4.0 International License (https://creativecommons.org/ licenses/by/4.0/), which permits use, sharing, adaptation, distribution, and reproduction in any medium or format as long as users cite the materials appropriately, provide a link to the Creative Commons license, and indicate the changes that were made to the original content. 